\title{
Two-Stage Conversion of High Free Fatty Acid Jatropha curcas Oil to Biodiesel Using Brønsted Acidic Ionic Liquid and KOH as Catalysts
}

\author{
Subrata Das, ${ }^{1}$ Ashim Jyoti Thakur, ${ }^{2}$ and Dhanapati Deka ${ }^{1}$ \\ ${ }^{1}$ Department of Energy, Tezpur University, Tezpur, Assam 784028, India \\ ${ }^{2}$ Department of Chemical Sciences, Tezpur University, Tezpur, Assam 784028, India \\ Correspondence should be addressed to Subrata Das; subrata0487@gmail.com
}

Received 17 August 2013; Accepted 29 December 2013; Published 30 March 2014

Academic Editors: K. Feng, R. Pedicini, and D. Sánchez

Copyright ( $\odot 2014$ Subrata Das et al. This is an open access article distributed under the Creative Commons Attribution License, which permits unrestricted use, distribution, and reproduction in any medium, provided the original work is properly cited.

Biodiesel was produced from high free fatty acid (FFA) Jatropha curcas oil (JCO) by two-stage process in which esterification was performed by Brønsted acidic ionic liquid 1-(1-butylsulfonic)-3-methylimidazolium chloride ([BSMIM]Cl) followed by KOH catalyzed transesterification. Maximum FFA conversion of $93.9 \%$ was achieved and it reduced from $8.15 \mathrm{wt} \%$ to $0.49 \mathrm{wt} \% \mathrm{under}$ the optimum reaction conditions of methanol oil molar ratio $12: 1$ and $10 \mathrm{wt} \%$ of ionic liquid catalyst at $70^{\circ} \mathrm{C}$ in $6 \mathrm{~h}$. The ionic liquid catalyst was reusable up to four times of consecutive runs under the optimum reaction conditions. At the second stage, the esterified JCO was transesterified by using $1.3 \mathrm{wt} \% \mathrm{KOH}$ and methanol oil molar ratio of $6: 1$ in $20 \mathrm{~min}$ at $64^{\circ} \mathrm{C}$. The yield of the final biodiesel was found to be $98.6 \%$ as analyzed by NMR spectroscopy. Chemical composition of the final biodiesel was also determined by GC-MS analysis.

\section{Introduction}

Biodiesel is chemically fatty acid alkyl esters of long-chain fatty acids derived from renewable sources such as vegetable oils and animal fats through the esterification and transesterification reactions of FFAs and triglycerides, respectively [1]. In transesterification, vegetable oil is allowed to be reacted with methanol in the presence of a catalyst which results into biodiesel and glycerol. Currently, more than $95 \%$ of the world biodiesel is produced from edible oils which are easily available on large scale from the agricultural industry [2]. However, continuous and large-scale production of biodiesel from edible oils has recently been of great concern because they compete with food materials, the food versus fuel dispute [3]. Also these expensive edible vegetable oils make the biodiesel production process costly as the feedstocks only account up to $75 \%$ of the total production cost [4]. In this context, the utilization of low cost nonedible oils as feedstock is very significant in developing countries [5]. However, the biodiesel production from nonedible oils by utilizing conventional homogenous alkaline catalysts like $\mathrm{NaOH}$ and
$\mathrm{KOH}$ is not possible due to the chances of saponification owing to its high free fatty acid (FFA) content $(>1 \% \mathrm{w} / \mathrm{w})$ [4]. Alternatively acid catalysts like sulphuric acid which are insensitive to the FFA content could catalyze the esterification and transesterification reaction simultaneously. But this approach is also unsuitable because of its slow reaction rate (4000 times slower as compared to alkali catalyzed transesterification) [6]. So none of the processes are suitable and convenient for crude oils. To address this issue a twostage process is developed where, in the first stage, acid catalysts (such as $\mathrm{H}_{2} \mathrm{SO}_{4}$ ) are utilized to lower the FFA content below $1 \mathrm{wt} \%$ followed by second stage alkaline catalyzed transesterification [7]. Again this traditional homogenous acid catalyst (sulphuric acid) suffers from some serious disadvantages such as nonreusability of the catalyst, problem of waste disposal, and requirement of costly equipment owing to the corrosive nature of the acid [8]. Recently, biodiesel production by two-stage process with regard to acidic ionic liquid catalysts and deep eutectic solvents has been reported in scientific literature [9-12]. Ionic liquids are adopted as catalysts because they are considered as designer solvents 
(1)
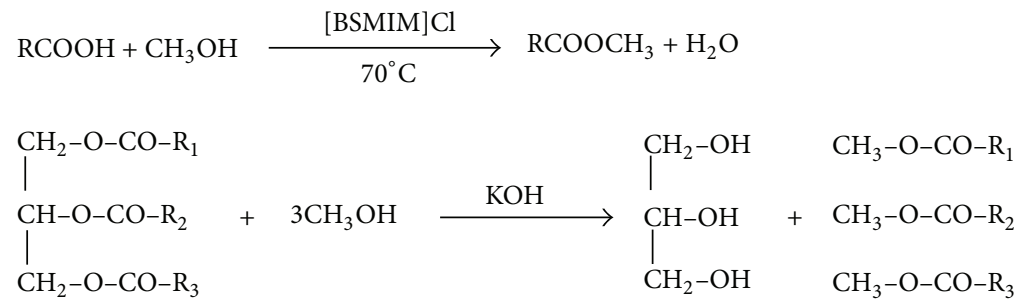

Scheme 1: Transesterification of triglycerides with alcohol (usually with methanol).

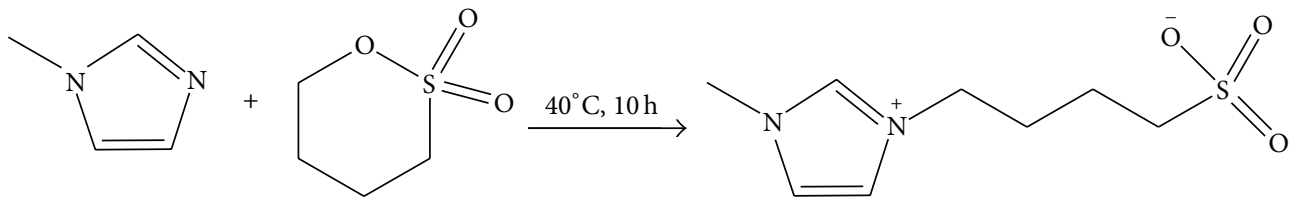

SCHEMe 2

and also have some green characteristics such as extremely low vapour pressure, nonflammability, reusability, and high thermal stability which makes the process clean $[13,14]$.

In present investigation, the aim is to report a new acidic ionic liquid for the pretreatment or esterification of crude JCO and to study the efficiency of the catalyst in esterification with regard to catalyst dosage and other reaction parameters such as methanol oil molar ratio, reaction temperature, and also reaction time and reusability of it. The particular ionic liquid can also be developed to a new and novel series of ionic liquid catalysts that can catalyze not only the esterification of FFAs of crude oil but also the esterification and transesterification reactions of crude oils for the production of biodiesel efficiently and simultaneously. Additionally the synthetic procedure of the ionic liquid is very simple and easy since no additional solvent is necessary and can be carried out simply by stirring at room temperature and is also atom efficient since no byproducts were generated during the synthesis. The reactions scheme adopted in this study is shown in Scheme 1.

\section{Materials and Methods}

2.1. Materials. Local dried Jatropha seeds were collected from the Kaliabor Nursery, Kaliabor, Assam, India. 1-Methylimidazole (99\%), 1,4-butane sultone ( $\geq 99 \%$ ), and 2-propanol (anhydrous, 99.5\%) were procured from Sigma Aldrich, India. Methanol ( $\geq 99 \%$, GC grade), hexane (fraction from petroleum), $\mathrm{HCl}$ (35\% for analysis), and $\mathrm{KOH}$ (analytical grade) were purchased from Merck India Limited. All the chemicals were used as received without any further purification.

2.2. Instruments. IR spectra were recorded in $\mathrm{KBr}$ pallets on a Nicolet (Impact 410) FT-IR spectrophotometer. ${ }^{1} \mathrm{H}$ and ${ }^{13} \mathrm{C}$ NMR spectra were recorded in a $400 \mathrm{MHz}$ NMR spectrophotometer (JEOL, JNM ECS) using tetramethylsilane (TMS) as the internal standard and coupling constants are expressed in Hertz. Elemental analyses were carried out in a Perkin-Elmer CHN analyzer (2400 series II).
The fatty acid composition was determined by GC-MS (Perkin Elmer Clarus 600) equipped with TCD detector and elite wax-5MS capillary column $(30 \mathrm{~m} \times 0.25 \mathrm{~mm} \times 0.25 \mu \mathrm{m})$. The GC oven was kept at $50^{\circ} \mathrm{C}$ for $2 \mathrm{~min}$, heated up to $250^{\circ} \mathrm{C}$ at the rate of $10^{\circ} \mathrm{C} / \mathrm{min}$ increase in temperature, and kept at this temperature for $5 \mathrm{~min}$ and the total analytical time taken was $27 \mathrm{~min}$. The carrier gas used for the purpose was helium and the flow rate was maintained at $1 \mathrm{~mL} / \mathrm{min}$. The UVvisible spectra were recorded on Shimadzu UV-1700 spectrophotometer. The solutions of the ionic liquid $(10 \mathrm{~m} \mathrm{~mol} / \mathrm{L})$, $\mathrm{H}_{2} \mathrm{SO}_{4}(10 \mathrm{~m} \mathrm{~mol} / \mathrm{L})$, and 4-nitroaniline $(10 \mathrm{~m} \mathrm{~mol} / \mathrm{L})$ were made in distilled water and their UV-vis spectra were carried out in the scale of 220-600 $\mathrm{nm}$ at room temperature. ESI-MS spectrum was obtained on Agilent 6410 Triple Quad MS-MS instrument.

The thermal analysis of the ionic liquid was measured by Pyris Diamond TG analyzer (Perkin Elmer) with a heating rate of $10^{\circ} \mathrm{C} / \mathrm{min}$ from room temperature to $500^{\circ} \mathrm{C}$. A high purity $\mathrm{N}_{2}$ gas $(99.99 \%)$ was used as a carrier gas at a flow rate of $10 \mathrm{~mL} \mathrm{~min}^{-1}$. In the experiment, a sample weighing approximately $28 \mathrm{mg}$ was used.

2.3. Extraction and Purification of JCO. The extraction of JCO was performed with the help of Soxhlet apparatus by using hexane (boiling point $65-70^{\circ} \mathrm{C}$ ) as solvent according to the AOAC method 2003.06. The oil was separated from solvent by means of rotary vacuum evaporator. The collected JCO was then filtered to remove all the solid impurities that may be present in the oil followed by heating at $100^{\circ} \mathrm{C}$ for $10 \mathrm{~min}$ to remove the remaining moisture [15].

\subsection{Preparation of Ionic Liquid}

2.4.1. Preparation of Zwitterion. The zwitterion was prepared according to the procedure reported in [16] and is illustrated in Scheme 2. In a $100 \mathrm{~mL}$ round-bottom flask, equal moles of 1-methylimidazole and 1,4-butane sultone were added and then the mixture was stirred for $10 \mathrm{~h}$ at $40^{\circ} \mathrm{C}$. The zwitterion formed appeared as white solid and was dried in 


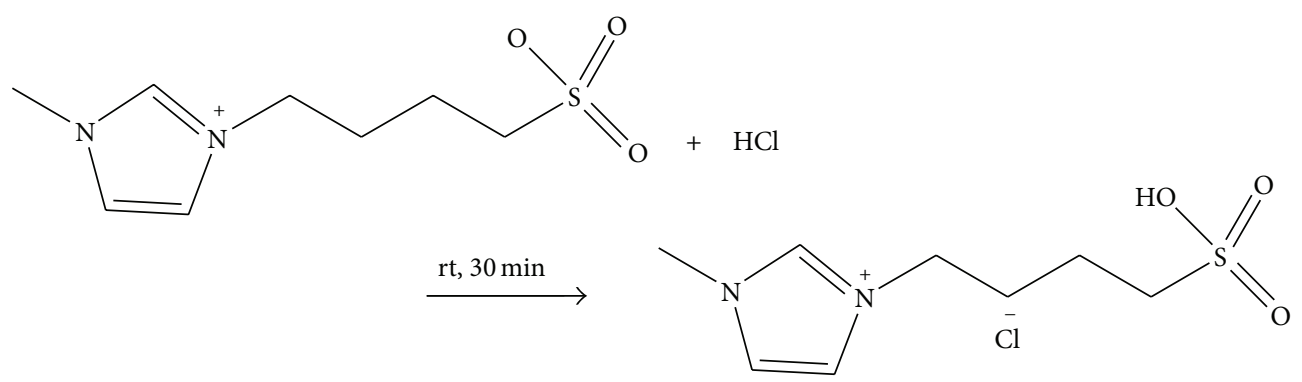

SCHEME 3

vacuum after being washed repeatedly with ether to remove unreacted reactants and impurities, if any. Quantitative yield of the product was obtained which was then characterized as follows: ${ }^{1} \mathrm{H}$ NMR $\left(400 \mathrm{MHz}, \mathrm{D}_{2} \mathrm{O}\right.$, TMS): $\delta$ ppm 1.61$1.68(\mathrm{~m}, 2 \mathrm{H}), 1.89-1.96(\mathrm{~m}, 2 \mathrm{H}), 2.82-2.87(\mathrm{~m}, 2 \mathrm{H}), 3.79(\mathrm{~s}$, $3 \mathrm{H}), 4.13(\mathrm{t}, J=7.9 \mathrm{~Hz}, 2 \mathrm{H}), 7.34-7.35(\mathrm{~m}, 1 \mathrm{H}), 7.40-7.41$ (m, 1H), $8.64(\mathrm{~s}, 1 \mathrm{H}) .{ }^{13} \mathrm{CNMR}\left(100 \mathrm{MHz}, \mathrm{D}_{2} \mathrm{O}, \mathrm{TMS}\right): \delta$ ppm 21.00, 28.17, 35.73, 48.99, 50.14, 122.25, 123.74, 136.06. IR (KBr): $\gamma(3423.13,3154.95,3102.97,1641.31,1572.49,1184.02$, 1041.36, 738.34, 606.81, 531.11). Elemental analysis: calc. for $\mathrm{C}_{8} \mathrm{H}_{14} \mathrm{~N}_{2} \mathrm{O}_{3} \mathrm{~S}$ : $\mathrm{C}$ 44.02, $\mathrm{H}$ 6.46, N 12.83. Found: $\mathrm{C} 43.43, \mathrm{H}$ 6.57, N 12.39\%.

2.4.2. Preparation of 1-(1-Butylsulfonic)-3-methylimidazolium Chloride ([BSMIM]Cl). The ionic liquid was prepared according to reaction Scheme 3. In this process a stoichiometric amount of $35 \% \mathrm{w} / \mathrm{w}$ concentrated hydrochloric acid was added to the zwitterion, stirred for $30 \mathrm{~min}$ at room temperature to form the viscous ionic liquid and then kept in vacuum desiccator prior to use. ${ }^{1} \mathrm{H}$ NMR $(400 \mathrm{MHz}$, methanol- $\mathrm{D}_{3}$, TMS): $\delta$ ppm 1.76-1.84 (m, 2H), 2.02-2.10 $(\mathrm{m}, 2 \mathrm{H}), 2.84(\mathrm{t}, J=7.9 \mathrm{~Hz}, 2 \mathrm{H}), 3.95(\mathrm{~s}, 3 \mathrm{H}), 3.98(\mathrm{~s}, 1 \mathrm{H})$, $4.27(\mathrm{t}, J=7.9 \mathrm{~Hz}, 2 \mathrm{H}), 7.60(\mathrm{~m}, 1 \mathrm{H}), 7.69(\mathrm{~m}, 1 \mathrm{H}), 9.01(\mathrm{~s}$, $1 \mathrm{H}) .{ }^{13} \mathrm{CNMR}(100 \mathrm{MHz}$, methanol-D 3 , TMS $): \delta$ ppm 22.93, $30.06,36.66,50.38,51.67,123.82,125.12,138.22$. IR (KBr): $\gamma$ (3420.69, 3159.18, 2955.67, 1639.73, 1574.35, 1176.56, 1040.00, 606.61, 536.67). Elemental analysis: calc. for $\mathrm{C}_{8} \mathrm{H}_{15} \mathrm{ClN}_{2} \mathrm{O}_{3} \mathrm{~S}$ : C 37.72, H 5.94, N 11.00. Found: C 37.53, H 5.97, N 10.79\%. ESI-MS positive mass peaks $(\mathrm{m} / \mathrm{z})\left([\mathrm{BSMIM}]^{+}\right): 219.0$, 437.1,655.1,873. 2. The thermal decomposition point of ionic liquid was $320^{\circ} \mathrm{C}$.

\subsection{Two-Step Biodiesel Production Process}

2.5.1. Ionic Liquid Catalyzed Esterification of JCO. The experiments were carried out in laboratory scale. Esterification was carried out by adding $20 \mathrm{gm}$ of JCO, appropriate methanol, and [BSMIM] Cl ionic liquid as catalyst in a three-neck round-bottom flask which was attached to a chilled water cooled condenser and placed on a hot plate magnetic stirrer. The reaction was prolonged for a specific amount of time at the desired temperature with vigorous stirring. After the reaction, the mixture was then centrifuged and a biphasic mixture was obtained. The esterified JCO forms the upper layer which was separated by simple decantation, while the lower layer forms the mixture of ionic liquid, excess methanol, and water generated from the reaction. The lower layer of the biphasic mixture was then subjected to vacuum distillation to separate the water and excess methanol from the ionic liquid. The recovered ionic liquid was washed with diethyl ether, dried under vacuum, and reused for the next run. The esterified JCO was heated to remove moisture, dried over anhydrous $\mathrm{Na}_{2} \mathrm{SO}_{4}$, and then further subjected to alkali catalyzed transesterification. Conversion data were calculated based on acid value determination by using the following equation [17]:

$$
\text { Conversion }(\%)=\left(\frac{a_{i}-a_{t}}{a_{i}}\right) \times 100,
$$

where $a_{i}$ is initial acid value of the mixture and $a_{t}$ is the acid value at any " $t$ " time.

2.5.2. Alkali Catalyzed Transesterification of JCO. The esterification was followed by transesterification of the esterified JCO by using $\mathrm{KOH}$ as catalyst according to the procedure reported earlier [18]. The reaction conditions were similar to those used during the esterification. In the reactor, the esterified JCO was heated and then mixed with the preheated solution of $1.3 \mathrm{wt} \%$ (based on the weight of JCO) $\mathrm{KOH}$ and methanol. A 6:1 molar ratio of methanol to JCO was taken and the mixture was stirred vigorously at $64^{\circ} \mathrm{C}$ for $20 \mathrm{~min}$. After the reaction, the components of the reaction mixture were allowed to be separated from each other in a separating funnel under gravity separation where two layers were formed. The upper layer was the desired biodiesel which was separated by decantation and then washed with warm distilled water to make it free from impurities such as soap, unreacted methanol, and residual $\mathrm{KOH}$. The washed biodiesel was then heated to remove moisture and dried over anhydrous $\mathrm{Na}_{2} \mathrm{SO}_{4}$ followed by analysis by Nuclear Magnetic Resonance (NMR) spectroscopy and GC-MS. The conversion of FAMEs was determined by the peak areas of the signals at 3.65 (protons of the methyl ester moiety) and at 2.31 (protons of the carbonyl methylene groups). The conversion was calculated by using the following simple equation [19]:

$$
C=\frac{2 A_{\mathrm{ME}}}{3 A_{\alpha-\mathrm{CH}_{2}}} \times 100,
$$

where $C$ is the conversion of JCO to the corresponding methyl ester, $A_{\mathrm{ME}}$ is the integration value of the protons of the methyl 


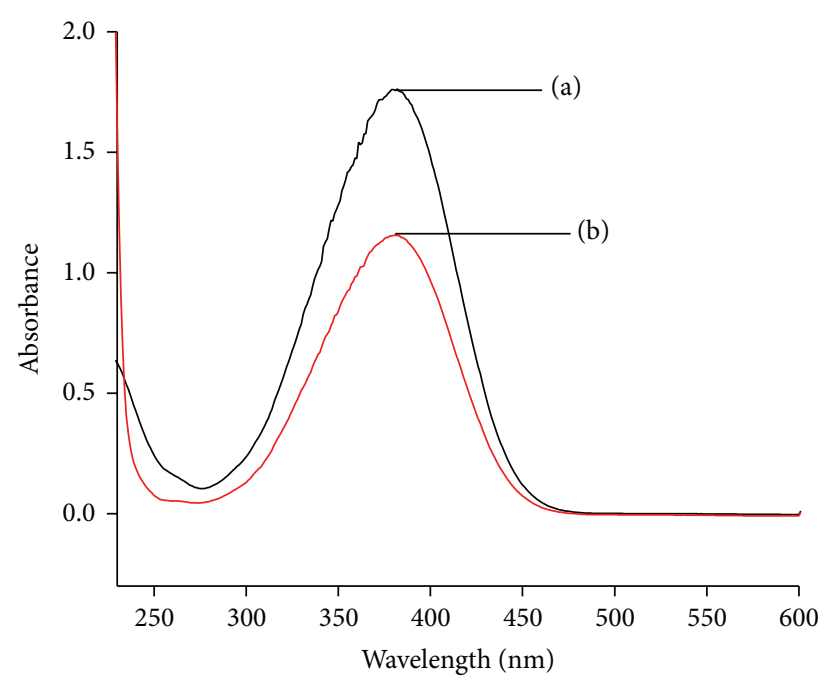

(a) Blank

(b) $[\mathrm{BSMIM}] \mathrm{Cl}$

FIgURE 1: Absorption spectra of 4-nitroaniline for Brønsted acids in distilled $\mathrm{H}_{2} \mathrm{O}$.

TABLE 1: Fatty acid composition and important properties of JCO.

\begin{tabular}{lcc}
\hline Sl. number & Properties & JCO \\
\hline & Fatty acid composition (wt $\%)$ & \\
\hline & Palmitic (16:0) & 16.34 \\
& Palmitoleic (16:1) & 0.65 \\
& Stearic (18:0) & 8.17 \\
& Oleic (18:1) & 47.30 \\
& Linoleic (18:2) & 27.53 \\
& Total saturated & 24.51 \\
& Total unsaturated & 75.48 \\
\hline 3 & FFA (wt $\%)$ & 8.156 \\
\hline 4 & Acid value (mgKOH/gm) & 16.232 \\
\hline 5 & Saponification value $(\mathrm{mgKOH} / \mathrm{gm})$ & 210.0 \\
\hline
\end{tabular}

esters (the strong singlet peak), and $A_{\alpha-\mathrm{CH}_{2}}$ is the integration value of the carbonyl methylene protons.

\section{Results and Discussion}

3.1. Feedstock Analysis. The physiochemical properties of JCO as determined according to the standard methods and the fatty acid methyl ester composition of JCO as determined by GC-MS chromatogram are given in Table 1. Five major peaks were observed in the chromatogram which was identified by comparing with the earlier reported publications [7] and the profiles from the NIST and Wiley GC-MS libraries. These five main components were identified as cis-9-hexadecenoic acid (0.65\%), hexadecanoic acid (16.34\%), cis-9, cis-12-octadecenoic acid (27.53\%), cis-9-octadecenoic acid (47.30\%), and octadecanoic acid $(8.17 \%)$.
TABLE 2: $H_{0}$ values of the ionic liquid in water at room temperature ${ }^{\mathrm{a}}$.

\begin{tabular}{lccccc}
\hline Entry & Brønsted acid & $A_{\max }$ & {$[\mathrm{I}](\%)$} & {$\left[\mathrm{IH}^{+}\right](\%)$} & $H_{0}$ \\
\hline 1 & Blank & 1.762 & 100.0 & 0 & - \\
2 & {$[$ BSMIM]Cl } & 1.154 & 65.494 & 34.506 & 1.268 \\
\hline \multicolumn{2}{l}{${ }^{\mathrm{a} C o n c e n t r a t i o n: ~} 10 \mathrm{~m} \mathrm{~mol} / \mathrm{L}$; indicator: } & 4-nitroaniline.
\end{tabular}

3.2. Determination of $\mathrm{H}_{0}$ Value of the Brønsted Acidic IL. The Brønsted acidity of the ionic liquid was determined from the determination of the Hammett acidity functions by using the following formula [20]:

$$
H_{0}=\mathrm{pK}(\mathrm{I})_{\mathrm{aq}}+\log \left(\frac{[\mathrm{I}]}{\left[\mathrm{IH}^{+}\right]}\right) \text {, }
$$

where $\mathrm{pK}(\mathrm{I})_{\mathrm{aq}}$ is the $\mathrm{pK}_{a}$ value of the indicator and [I] and $\left[\mathrm{IH}^{+}\right]$are, respectively, the molar concentrations of the unprotonated and protonated forms of the indicator, which can usually be determined by UV-visible spectroscopy.

4-Nitroaniline (Hammett content is 0.99; concentration is $10 \mathrm{mmol} / \mathrm{L}$ ) was used as an indicator in water [21] and the results are shown in Figure 1. The maximum absorbance of the unprotonated form of the indicator was observed at $382 \mathrm{~nm}$ in water as shown in the Figure 1, which is the same as the observed earlier [21]. The absorbance maxima decrease with the addition of acid. $[\mathrm{I}] /\left[\mathrm{IH}^{+}\right]$ratio could be determined by measuring the absorbance differences and then the Hammett function $\left(H_{0}\right)$ is calculated (see Table 2).

\section{3. [BSMIM]Cl-Catalyzed Esterification Reaction of JCO}

3.3.1. Effect of the Catalyst Loading. The catalyst loading is one of the most important factors that influence the esterification reaction and it is shown in Figure 2(a). The catalyst loading 


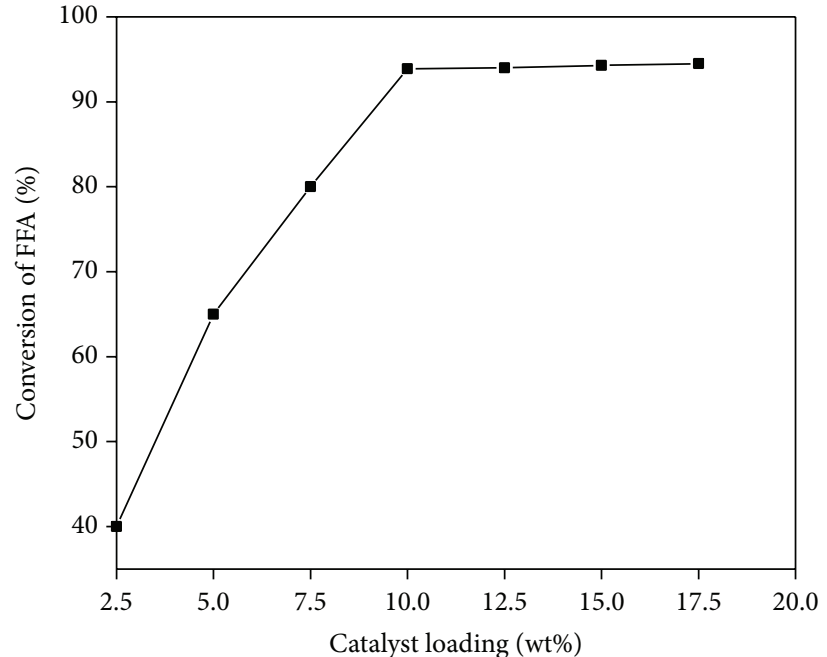

(a)

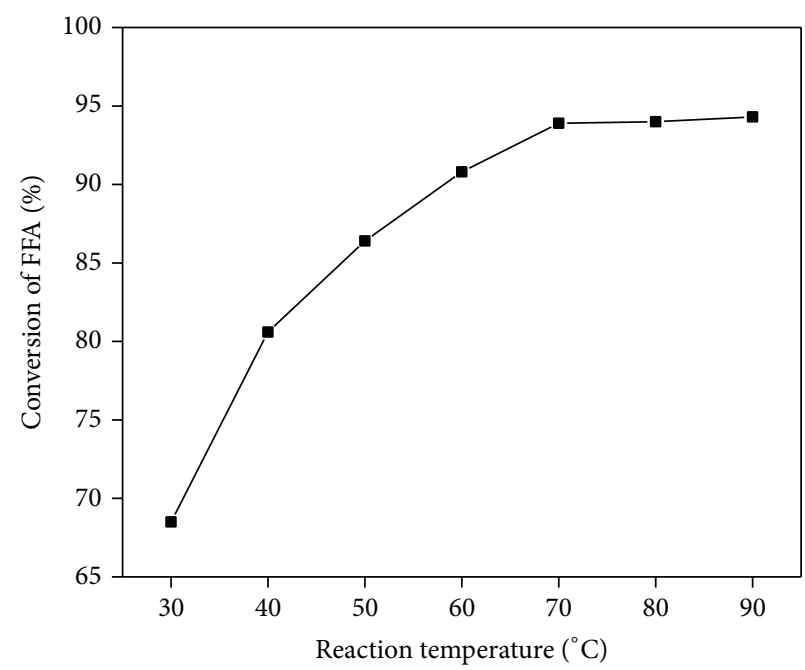

(c)

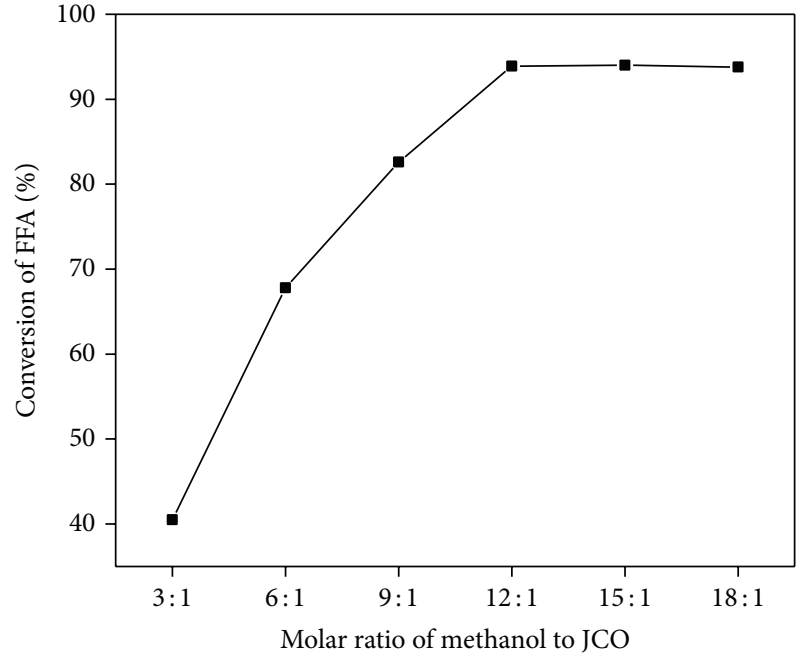

(b)

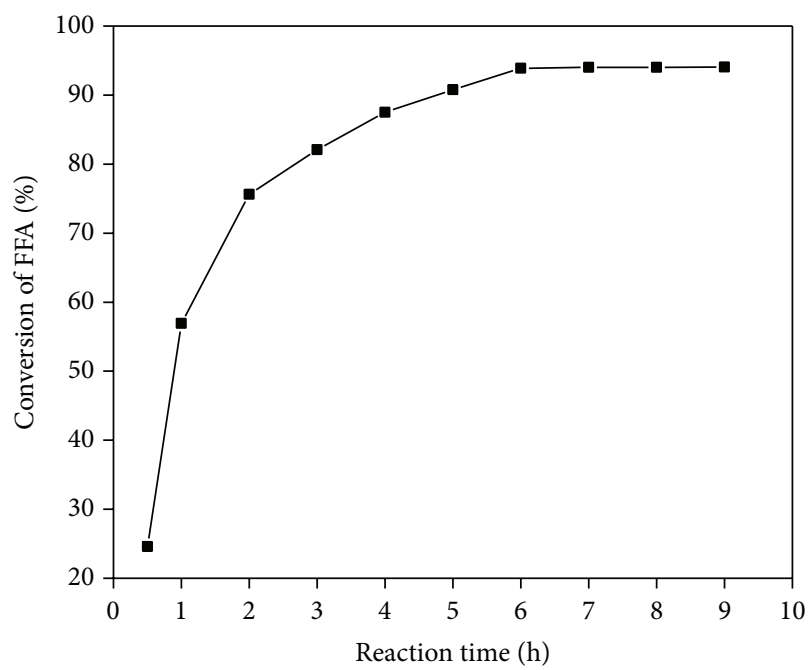

(d)

FIGURE 2: (a) Effect of the loading of [BSMIM]Cl on FFA conversion. Reaction conditions: $n$ (methanol) $: n(\mathrm{JCO})=12: 1 ; 70^{\circ} \mathrm{C} ; 6 \mathrm{~h}$. (b) Effect of molar ratio of methanol to JCO on FFA conversion. Reaction conditions: $n(\mathrm{JCO}): n([\mathrm{BSMIM}] \mathrm{Cl}):=1: 0.32 ; 70^{\circ} \mathrm{C} ; 6 \mathrm{~h}$. (c) Effect of the reaction temperature on FFA conversion. Reaction conditions: $n$ (methanol) $: n(\mathrm{JCO}): n([\mathrm{BSMIM}] \mathrm{Cl})=12: 1: 0.32 ; 6 \mathrm{~h}$. (d) Effect of the reaction time on FFA conversion. Reaction conditions: $n$ (methanol) $: n(\mathrm{JCO}): n([\mathrm{BSMIM}] \mathrm{Cl})=12: 1: 0.32 ; 70^{\circ} \mathrm{C}$.

was varied in the range of $2.5-17.5 \mathrm{wt} \%$ (based on the weight of JCO) and FFA conversion was determined. From the figure it could be seen that FFA conversion was low at lower catalyst loading and it increased with the increment of catalyst loading. The maximum conversion of $93.9 \%$ was observed with $10 \mathrm{wt} \%$ of catalyst loading and further increase did not increase the conversion so much. Therefore the optimum catalyst loading was chosen as $10 \mathrm{wt} \%$.

3.3.2. Effect of Molar Ratio of Methanol to JCO. In esterification, generally an excess of methanol is necessary for the complete conversion of FFA. Additionally, since the ionic liquid catalyst was soluble in methanol, an excess of methanol should increase the reaction rate due to the enhancement of contact area between the reactants. Keeping this view in mind, the molar ratio of methanol to JCO was varied from $3: 1$ to $18: 1$ and the results are shown in the Figure 2(b). The results indicate that the FFA conversion increases with the increase of molar ratio of methanol to oil and reaches its highest value of $93.9 \%$ with $12: 1$ molar ratio, beyond which a slight increase in conversion is obtained. Therefore, the optimum methanol to JCO oil ratio was taken as $12: 1$.

3.3.3. Effect of Reaction Temperature. The reaction temperature has an important role in esterification reaction. Generally reaction rate is enhanced with the rise in temperature, the effect of which on FFA conversion is shown in Figure 2(c). The figure reveals that under similar reaction conditions, higher FFA conversion is achieved at elevated temperature than at low temperature which may be due to the increment 


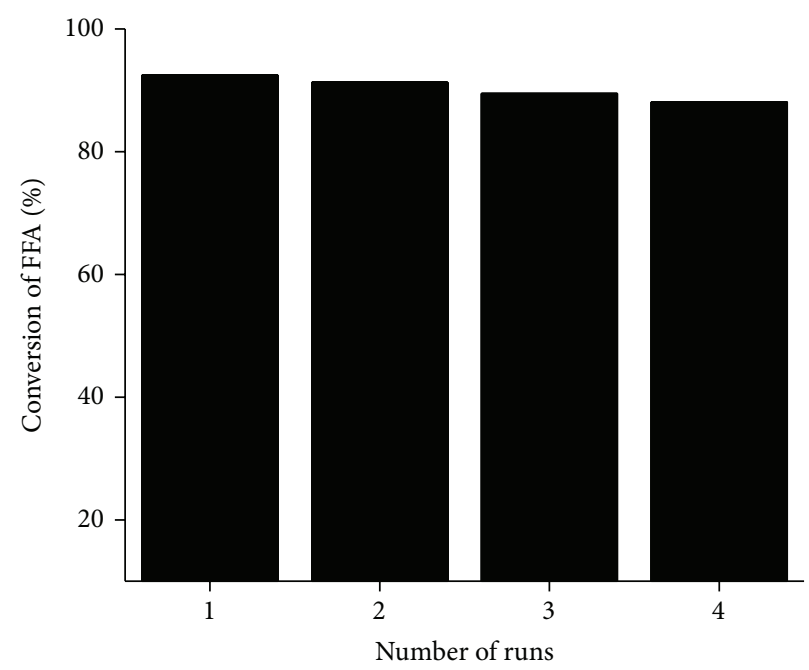

Figure 3: Reusability study of [BSMIM]Cl.

of the reaction rate at higher temperature. At low reaction temperature of $30^{\circ} \mathrm{C}$, FFA conversion of $68.5 \%$ was achieved and it reached $93.9 \%$ at $70^{\circ} \mathrm{C}$. The conversion did not improve much with further increase in temperature up to $90^{\circ} \mathrm{C}$ which means that the reaction attends the equilibrium at $70^{\circ} \mathrm{C}$. Therefore, the suitable reaction temperature was chosen as $70^{\circ} \mathrm{C}$.

3.3.4. Effect of Reaction Time. The influence of reaction time is the last but not the least very important factor in esterification of FFA. The influence of reaction is presented in Figure 2(d). A reaction usually approaches equilibrium with increase in reaction time and then at a certain interval of time it attends the equilibrium. So it is very important to find out the time interval at which the esterification reaction reaches the equilibrium. It is evident from the figure that the FFA conversion increases with the increase in reaction time. The sample of the reaction mixture was extracted from the reactor at $1 \mathrm{~h}$ interval of time and the FFA conversion was determined. It was observed that the FFA conversion increases sharply at the initial stage of the reaction and then increases slowly up to $6 \mathrm{~h}$ of time. The conversion of $93.9 \%$ was obtained in $6 \mathrm{~h}$ and after that the conversion remained nearly constant. The result confirms that the catalyst is sufficiently active in esterification of FFA and reaches equilibrium only in $6 \mathrm{~h}$ at $70^{\circ} \mathrm{C}$. So, $6 \mathrm{~h}$ was taken as the optimum reaction time.

3.4. Reusability Study of [BSMIM]Cl in Esterification of FFA of JCO. The catalytic activity of the recycled ionic liquid (Table 3 and Figure 3 ) was investigated by performing esterification reactions for four consecutive runs under the optimum reaction conditions as determined earlier. The [BSMIM]Cl ionic liquid could be reused at least four times with any significant decrease in catalytic activity. The slight decrease in catalytic activity of ionic liquid may be due to gradual loss of ionic liquid in each run. The FT-IR spectrum comparison of fresh and the recovered catalyst after four runs

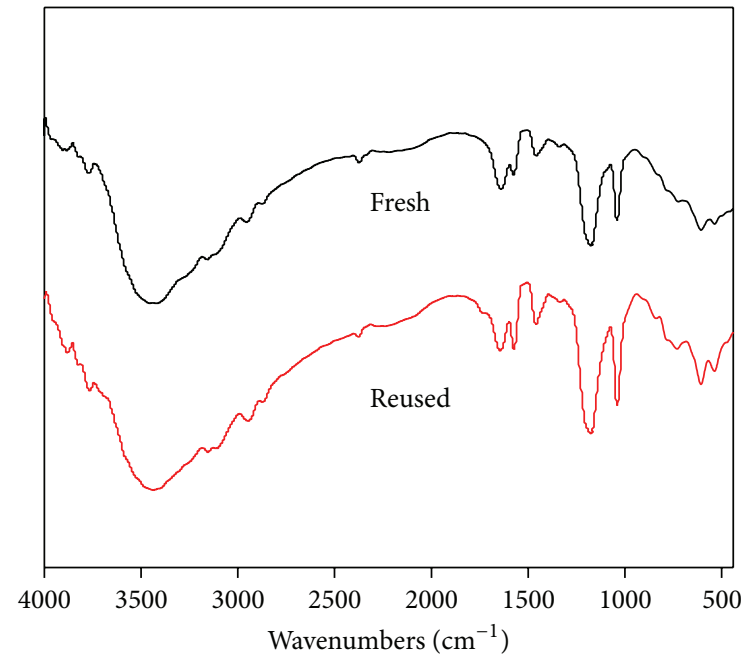

FIGURE 4: FT-IR spectrum comparison of the fresh catalyst and the four-time used catalyst.

depicted that there is no significant change in the ionic liquid structure (Figure 4). The reusability study reveals that up to four runs the esterified JCO had FFA content less than $1 \mathrm{wt} \%$ and hence could be used for the second step alkali catalyzed transesterification reaction for the production of biodiesel. These results indicate that the catalyst was very stable under these reaction conditions.

3.5. Alkali Catalyzed Transesterification. The esterified JCO used for the alkali catalyzed transesterification has $0.49 \mathrm{wt} \%$ FFA. This low FFA content of the oil makes it suitable for the alkali catalyzed transesterification process. Therefore, transesterification was carried out with $1.3 \mathrm{wt} \% \mathrm{KOH}$ as catalyst, 6:1 molar ratio of methanol to JCO, and reaction temperature of $64^{\circ} \mathrm{C}$ for $20 \mathrm{~min}$, and FAME conversion of $98.6 \%$ was obtained. Therefore the ester content in the final 


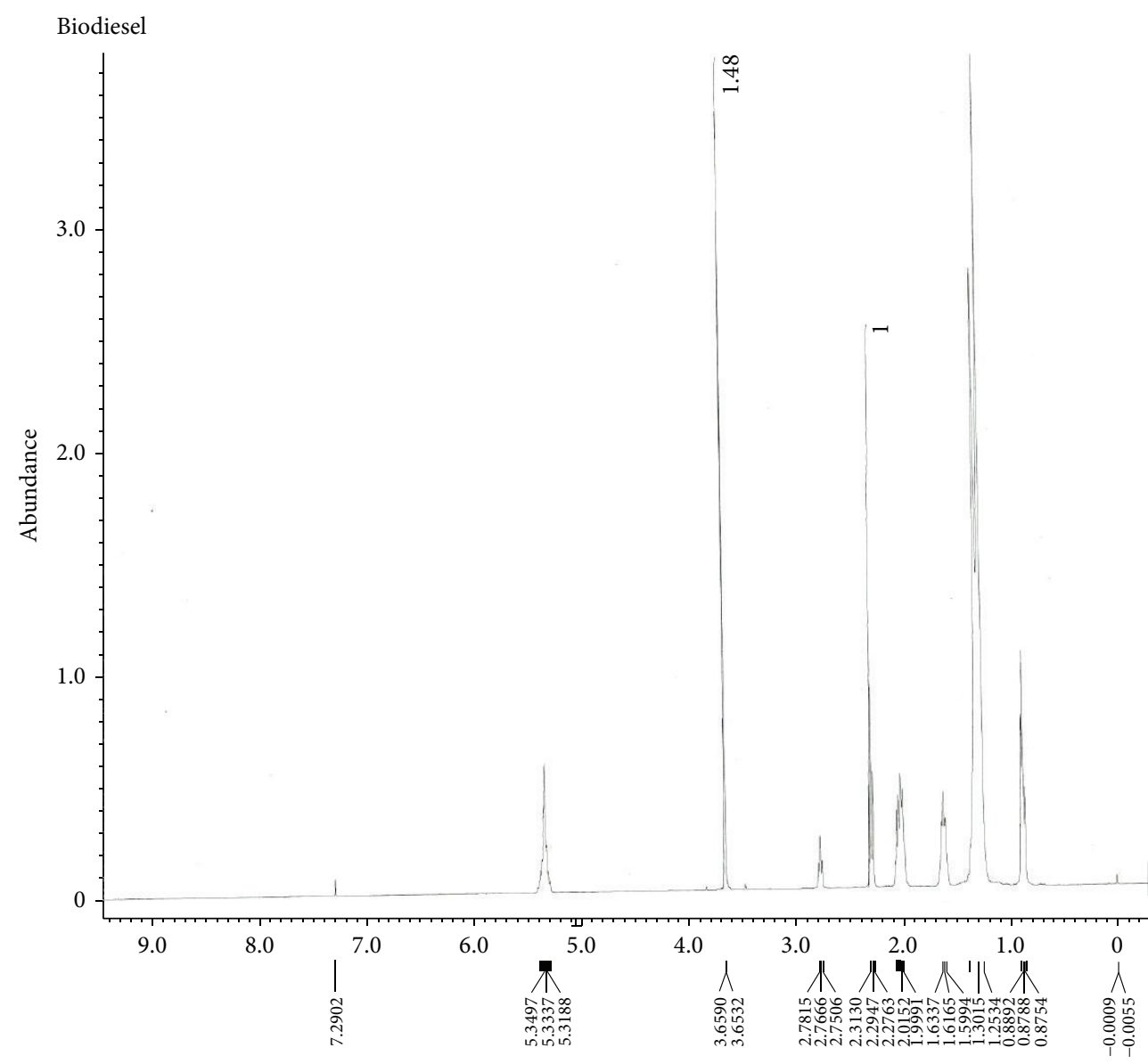

X: parts per million: ${ }^{1} \mathrm{H}$

FIgURE 5: ${ }^{1} \mathrm{H}$ NMR spectra of final biodiesel.

TABLE 3: Reusability study of ionic liquid ${ }^{\mathrm{b}}$.

\begin{tabular}{lccc}
\hline Run & Conversion of FFA (\%) & Acid value & FFA (wt\%) \\
\hline 1 & 92.5 & 1.217 & 0.61 \\
2 & 91.3 & 1.412 & 0.70 \\
3 & 89.5 & 1.704 & 0.85 \\
4 & 88.1 & 1.932 & 0.97 \\
\hline${ }^{\mathrm{b}}$ Reaction conditions: $n$ (methanol) $: \mathrm{JCO}: n([\mathrm{BSMIM}] \mathrm{Cl})=12: 1: 0.32 ; 70^{\circ} \mathrm{C} ;$
\end{tabular}
$6 \mathrm{~h}$.

TABLE 4: Fatty acid composition of final biodiesel.

\begin{tabular}{lcc}
\hline FAMEs composition & Structure & Fatty acids (wt\%) \\
\hline Methyl palmitate & C16:0 & 16.08 \\
Methyl palmitoleate & $\mathrm{C} 16: 1$ & 0.77 \\
Methyl stearate & $\mathrm{C} 18: 0$ & 11.04 \\
Methyl cleate & $\mathrm{C} 18: 1$ & 46.50 \\
Methyl linoleate & $\mathrm{C} 18: 2$ & 25.61 \\
\hline
\end{tabular}

biodiesel meets the limit of $96.5 \%$ of European Biodiesel Standards (EN 14214).

\subsection{Analysis of Final Biodiesel}

3.6.1. NMR Spectroscopic Analysis. The final biodiesel was analyzed by NMR spectroscopy and is shown in Figures 5 and 6 . The peaks at $3.65 \mathrm{ppm}$ of methoxy $\left(-\mathrm{OCH}_{3}\right)$ group and $2.31 \mathrm{ppm}$ of $\alpha-\mathrm{CH}_{2}$ protons in ${ }^{1} \mathrm{H}$ NMR spectra and at 174.25 ppm of ester carbonyl (-COO-) and 51.42 ppm of C$\mathrm{O}$ in ${ }^{13} \mathrm{C}$ NMR spectra confirm the presence of methyl esters in the biodiesel sample.

3.6.2. GC/MS Analysis. The chemical composition of the final biodiesel was determined by GC-MS analysis. Total ion chromatogram (TIC) (Figure 7) shows that there are five major peaks of five fatty acid methyl esters which are identified from NIST and Wiley GC/MS libraries and are listed in Table 4.

\section{Conclusion}

Maximum FFA conversion of $93.9 \%$ was obtained at mild reaction temperature of $70^{\circ} \mathrm{C}$ and the esterified JCO produced could be separated simply by centrifugation. The ionic 


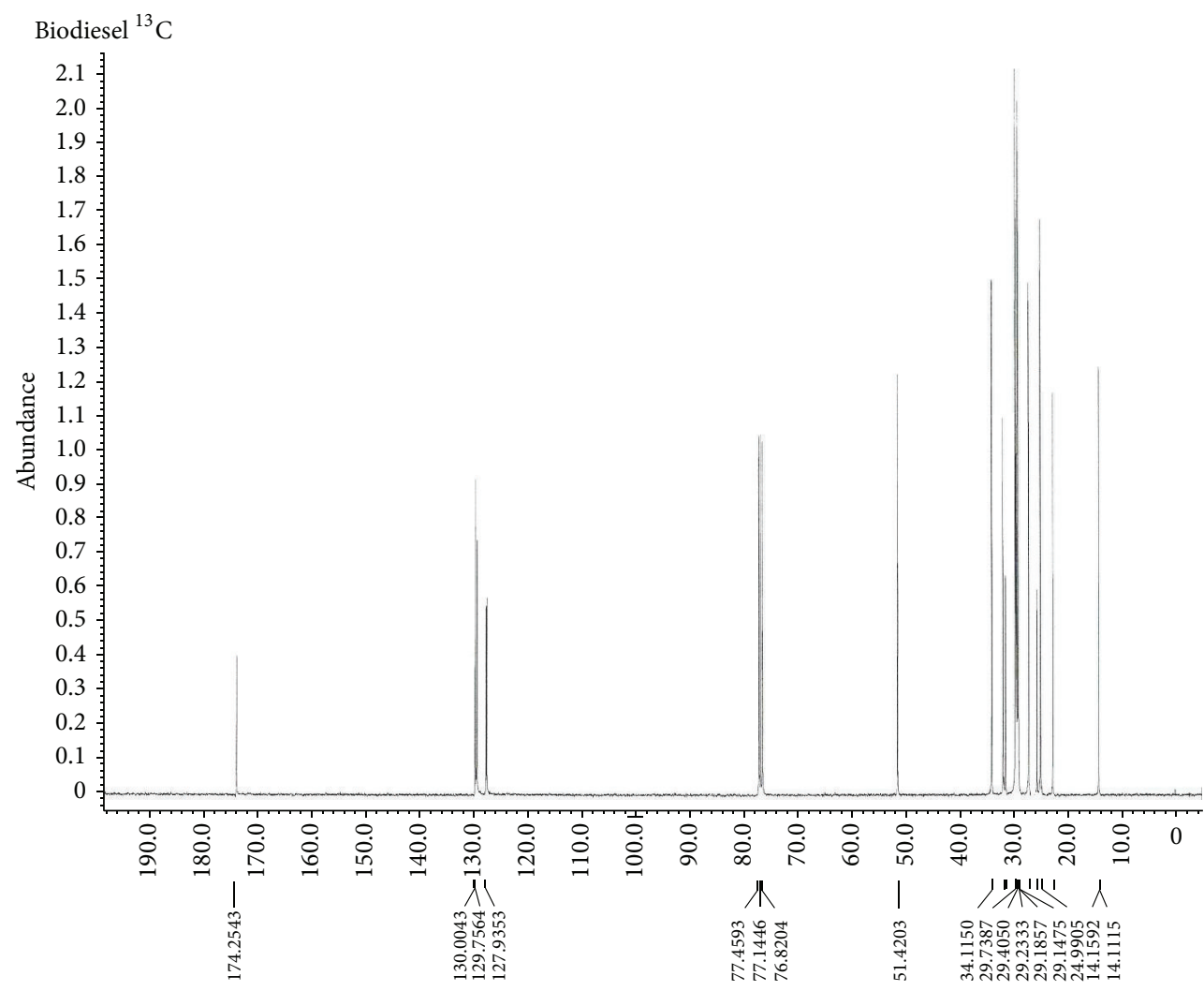

X: parts per million: ${ }^{13} \mathrm{C}$

FIgURE 6: ${ }^{13} \mathrm{C}$ NMR spectra of final biodiesel.

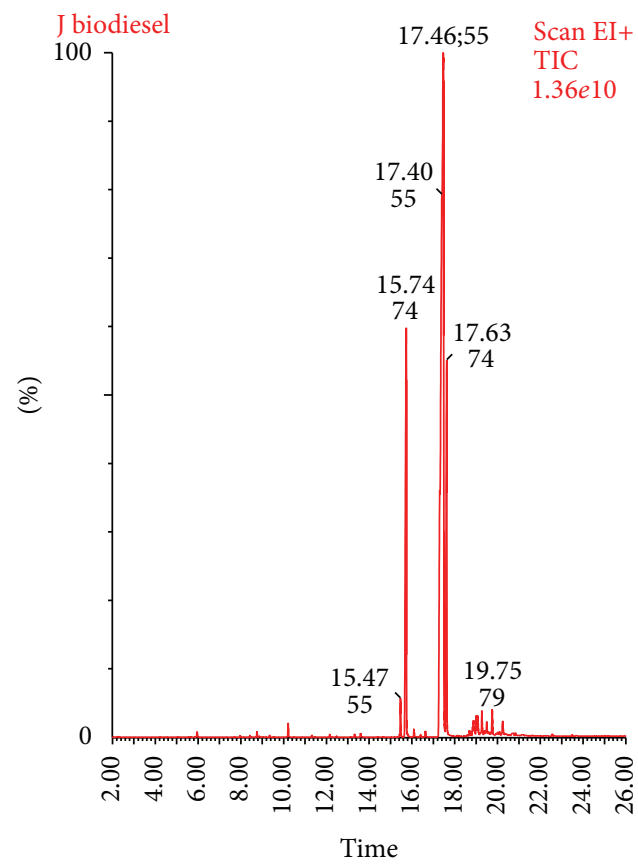

FIgURE 7: GC-MS of final biodiesel. 
liquid was also reusable up to four times with a slight loss in catalytic activity. Therefore, the utilization of [BSMIM]Cl in pretreatment process paves the way for the application of low cost feedstocks such as JCO for the continuous biodiesel production and lowers the overall cost in this process.

\section{Conflict of Interests}

The authors declare that there is no conflict of interests regarding the publication of this paper.

\section{Acknowledgment}

This work was financially supported by DST Indo-Finnish International Collaborative Green Chemistry Project.

\section{References}

[1] V. B. Borugadda and V. V. Goud, "Biodiesel production from renewable feedstocks: status and opportunities," Renewable and Sustainable Energy Reviews, vol. 16, pp. 4763-4784, 2012.

[2] M. M. Gui, K. T. Lee, and S. Bhatia, "Feasibility of edible oil vs. non-edible oil vs. waste edible oil as biodiesel feedstock," Energy, vol. 33, no. 11, pp. 1646-1653, 2008.

[3] A. A. Refaat, "Different techniques for the production of biodiesel from waste vegetable oil," International Journal of Environmental Science and Technology, vol. 7, no. 1, pp. 183-213, 2010.

[4] F. Ma and M. A. Hanna, "Biodiesel production: a review," Bioresource Technology, vol. 70, no. 1, pp. 1-15, 1999.

[5] K. Pramanik, "Properties and use of Jatropha curcas oil and diesel fuel blends in compression ignition engine," Renewable Energy, vol. 28, no. 2, pp. 239-248, 2003.

[6] S. P. Singh and D. Singh, "Biodiesel production through the use of different sources and characterization of oils and their esters as the substitute of diesel: a review," Renewable and Sustainable Energy Reviews, vol. 14, no. 1, pp. 200-216, 2010.

[7] H. J. Berchmans and S. Hirata, "Biodiesel production from crude Jatropha curcas L. seed oil with a high content of free fatty acids," Bioresource Technology, vol. 99, no. 6, pp. 1716-1721, 2008.

[8] M. Dokić, Z. Kesić, J. Krstić, D. Jovanović, and D. Skala, "Decrease of free fatty acid content in vegetable oil using silica supported ferric sulfate catalyst," Fuel, vol. 97, pp. 595-602, 2012.

[9] Y. A. Elsheikh, Z. Man, M. A. Bustam, S. Yusup, and C. D. Wilfred, "Brønsted imidazolium ionic liquids: synthesis and comparison of their catalytic activities as pre-catalyst for biodiesel production through two stage process," Energy Conversion and Management, vol. 52, no. 2, pp. 804-809, 2011.

[10] Z. Man, Y. A. Elsheikh, M. A. Bustam, S. Yusup, M. I. A. Mutalib, and N. Muhammad, "A Brønsted ammonium ionic liquid- $\mathrm{KOH}$ two-stage catalyst for biodiesel synthesis from crude palm oil," Industrial Crops and Products, vol. 41, pp. 144-149, 2012.

[11] A. Hayyan, M. A. Hashim, M. Hayyan, F. S. Mjalli, and I. M. AlNashef, "A novel phosphonium-based deep eutectic catalyst for biodiesel production from industrial low grade crude palm oil," Chemical Engineering Science, vol. 92, pp. 81-88, 2013.

[12] A. Hayyan, M. A. Hashim, M. Hayyan, F. S. Mjalli, and I. M. AlNashef, "A novel ammonium based eutectic solvent for the treatment of free fatty acid and synthesis of biodiesel fuel," Industrial Crops and Products, vol. 46, pp. 392-398, 2013.
[13] M. Freemantle, "Designer solvents-ionic liquids may boost clean technology development," Chemical \& Engineering News, vol. 76, pp. 32-37, 1998.

[14] M. Petkovic, K. R. Seddon, L. P. N. Rebelo, and C. Silva Pereira, "Ionic liquids: a pathway to environmental acceptability," Chemical Society Reviews, vol. 40, no. 3, pp. 1383-1403, 2011.

[15] S. Jain and M. P. Sharma, "Kinetics of acid base catalyzed transesterification of Jatropha curcas oil," Bioresource Technology, vol. 101, no. 20, pp. 7701-7706, 2010.

[16] J. Gui, X. Conga, D. Liu, X. Zhang, Z. Hu, and Z. Sun, "Novel Brønsted acidic ionic liquid as efficient and reusable catalyst system for esterification," Catalysis Communications, vol. 5, pp. 473-477, 2004.

[17] V. SathyaSelvabala, D. K. Selvaraj, J. Kalimuthu, P. M. Periyaraman, and S. Subramanian, "Two-step biodiesel production from Calophyllum inophyllum oil: optimization of modified $\beta$-zeolite catalyzed pre-treatment," Bioresource Technology, vol. 102, no. 2, pp. 1066-1072, 2011.

[18] H. Lu, Y. Liu, H. Zhou, Y. Yang, M. Chen, and B. Liang, "Production of biodiesel from Jatropha curcas L. oil," Computers and Chemical Engineering, vol. 33, no. 5, pp. 1091-1096, 2009.

[19] G. Gelbard, O. Brès, R. M. Vargas, F. Vielfaure, and U. F. Schuchardt, " $\mathrm{H}$ nuclear magnetic resonance determination of the yield of the transesterification of rapeseed oil with methanol," Journal of the American Oil Chemists' Society, vol. 72, no. 10, pp. 1239-1241, 1995.

[20] G. Cheng, X. Duan, X. Qi, and C. Lu, "Nitration of aromatic compounds with $\mathrm{NO}_{2}$ /air catalyzed by sulfonic acidfunctionalized ionic liquids," Catalysis Communications, vol. 10, no. 2, pp. 201-204, 2008.

[21] X. Liu, H. Ma, Y. Wu et al., "Esterification of glycerol with acetic acid using double $\mathrm{SO}_{3} \mathrm{H}$-functionalized ionic liquids as recoverable catalysts," Green Chemistry, vol. 13, no. 3, pp. 697701, 2011. 

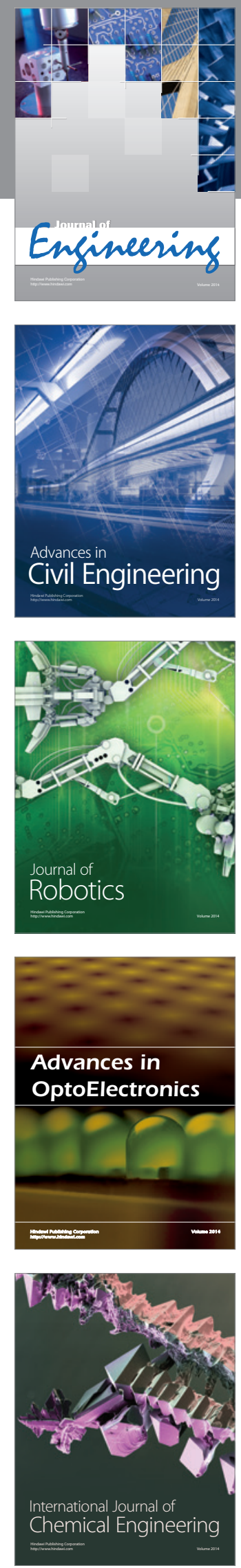

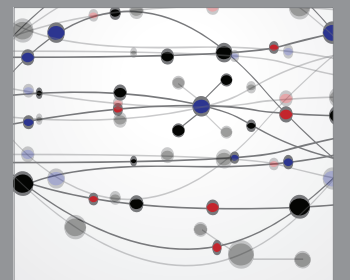

The Scientific World Journal
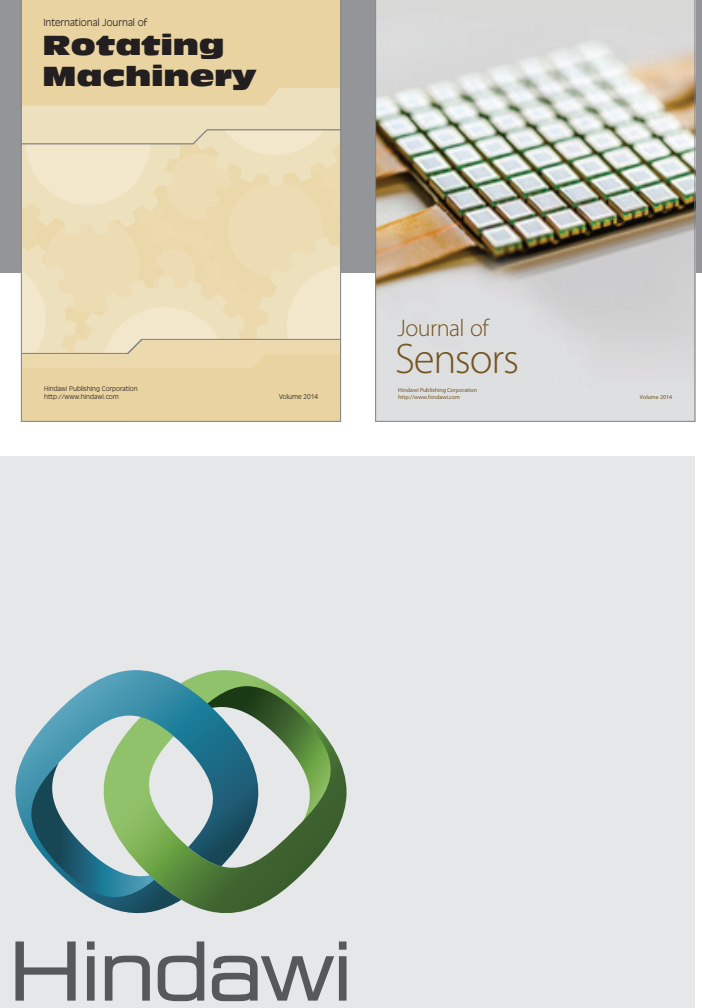

Submit your manuscripts at http://www.hindawi.com
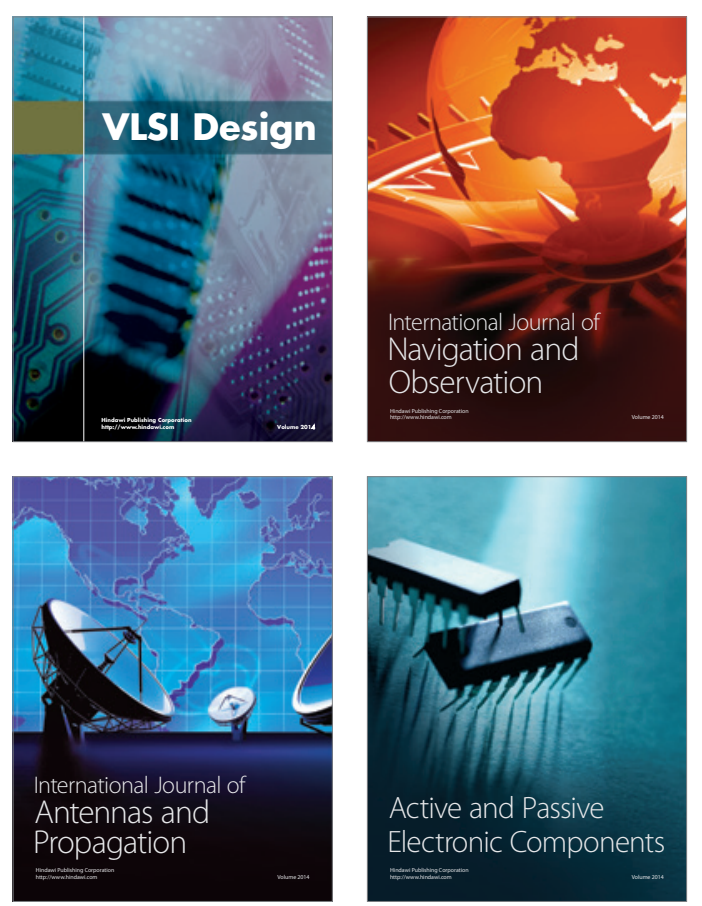
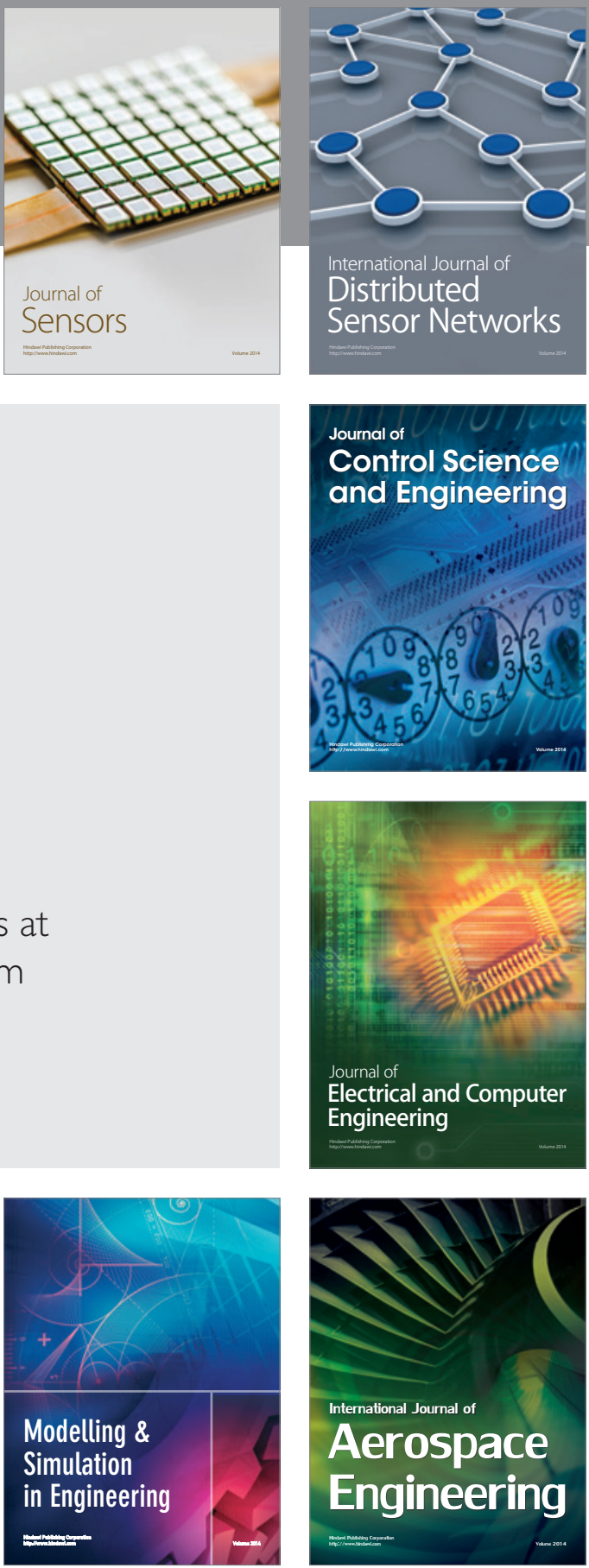

Journal of

Control Science

and Engineering
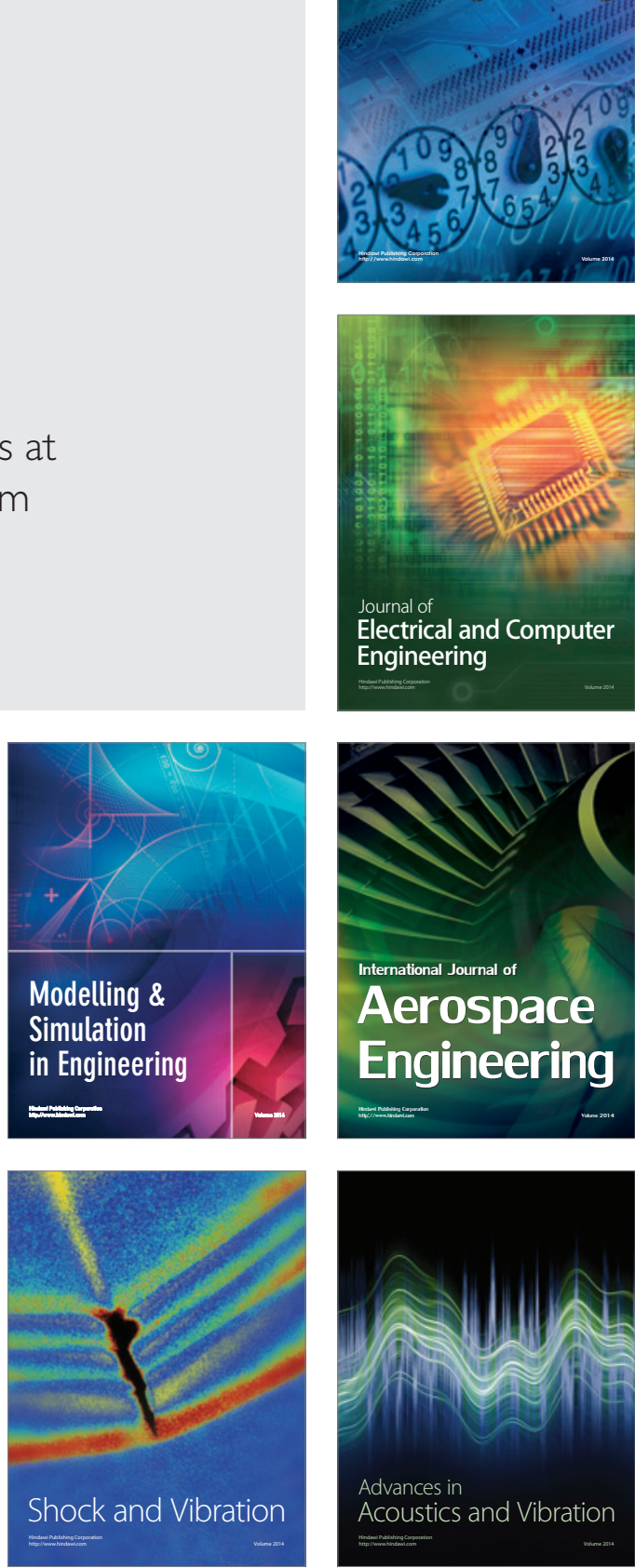